\title{
GENERIC HEALTH-RELATED QUALITY OF LIFE AMONG ADULT OUTPATIENTS IN SAUDI ARABIA
}

\author{
Lamya Alabdulkarim ${ }^{1 *}$, and Mishal Aldaihan ${ }^{2}$ \\ ${ }^{1}$ Dr. Department of Rehabilitation Sciences, College of Applied Medical Sciences, King Saud \\ University, Saudi Arabia, laalabdulkarim@ksu.edu.sa \\ ${ }^{2}$ Dr. Department of Rehabilitation Sciences, College of Applied Medical Sciences, King Saud \\ University, Saudi Arabia mishal.aldaihan@ksu.edu.sa2 \\ ${ }^{*}$ Corresponding Author
}

\begin{abstract}
Background: Health-related factors differ from one culture to another based on provided health services and the prevalence of different diseases. Accordingly, identifying these factors is crucial to improve the overall quality of life. The objective of this study is to explore the factors affecting health-related quality of life among adult outpatients living in Saudi Arabia.

Methods: A cross-sectional study using a 50-item questionnaire investigated different aspects of healthrelated quality of life in 10 Saudi hospitals in Riyadh region between the years 2018-2019. A Linear regression analysis was performed to determine the predictors influencing health-related quality of life.

Results: A total of 806 participants from different regions of Saudi Arabia responded to this customized questionnaire. The average HRQOL score was 285.23 (27.47) out of a maximum score of 350. The highest average score was achieved in the social, environmental, and economic domain 6.99 (0.78). The lowest average score was achieved in health and activity of daily living domain $5.29(0.70)$.

Conclusion: The Saudi adult patient population had an above-average level of HRQOL. This result indicates that culture does play a factor in impacting the generic outcome measurement of HRQOL.
\end{abstract}

Keywords: Health-related, Quality of Life, Saudi Arabia, Outcome measurement

\section{INTRODUCTION}

Quality of life can be defined as the measure of a person's or community's well-being (1). It involves an assessment of both positive and negative aspects of their daily life (2). It should be noted that people usually perceive their quality of life depending on different factors, such as their cultural, religious, and socioeconomic levels, which makes perceived Quality of life highly variable among individuals (3-5). Furthermore, outcome measurement of quality of life considers the engagement of individuals into social activities as well as their psychological well-being and their satisfaction with their lives (6). Accordingly, Quality of life should be evaluated as a compound assessment that involves multiple interactions depending on people's beliefs and perspectives (7). 
The most important aspect of Quality of life as a whole is that which pertains to a person's health, henceforth, health related quality of life (HRQOL). It is defined as the living values that can be improved through changing thoughts, social challenges, or different functional conditions influenced by particular health status, managed care plans, or an injury $(8,9)$. However, a patients' perceptions of personal HRQOL, is highly variable as it is prominently based on cultural, social, and educational backgrounds (10); and in many cases their comparison with other patients (11). Nevertheless, HRQOL should be measured to evaluate the impact of a medical condition or procedure on patients' quality of life (12). This assessment of life quality can differ from one country to another, and it has not been evaluated in Saudi Arabia. Accordingly, the present study investigates the factors affecting the HRQOL in Saudi Arabia.

\section{MATERIALS AND METHODS}

\subsection{Study Design}

This cross-sectional study was carried out in Riyadh region, Saudi Arabia between the years 2018-2019. Patients from 10 hospitals were included, representing five major government hospitals and primary care settings, two university hospitals, and three private hospitals. The participants represented a heterogeneous sample of patients comprising different age groups, gender, diseases, and relevant socio-demographic factors. Inclusion criteria were (a) receiving clinical services at a specific clinic for at least three months, (b) being 18 years or older, and (c) being capable of within normal cognitive and communication capabilities so as to understand and respond to the questionnaire.

\subsection{Data Collection}

A self-reporting web-based questionnaire using an iPad was distributed. The questionnaire was customized to suit the language and culture of the participants and was thus written in Arabic (13). This questionnaire was modelled after several standardized tools including WHO instrument: https://www.who.int/toolkits/whogol. The four domains in measuring HRQOL were included with an added domain on communication as an integral part of physician-patient health care delivery. Items were designed to fit the Saudi Arabian culture. It is worth mentioning that this tool has been validated using Cronbach alpha testing. Kaiser-Meyer-Olkin Measure of Sampling Adequacy (KMO) value was 0.927, with a significant Bartlett's Test of Sphericity. Face and content validity were reviewed by 4 co-researchers as well as usability was tested by 29 senior student clinicians and two clinical practitioners.

The Arabic generic health related quality of life questionnaire (AHRQOL) included 50 items to evaluate five different domains, including health and activity of daily living; emotion, religion, social, environment, and economic factors; work and study aspects; and communication (See Appendix A). Data was collected between 2018- 2019. The research clinicians supervised and checked each questionnaire for completeness of responses.

\subsection{Statistical Analyses}

Descriptive analysis for categorical variables was displayed as frequencies and percentiles. Numerical variables were evaluated through means and standard deviation. Univariate analysis, including the frequency distribution and percentile, was conducted for the respondents' demographic characteristics.

\subsection{Ethical Considerations}

Ethical approval was acquired from the Institutional Review Boards of King Saud University, College of Medicine (No. 089-37/38; No. E-17-2563). Prior to participating, senior multidisciplinary clinicians explained to each patient the study and requested written consent.

\section{RESULTS}

The socio-demographics of 806 responders are shown in Table 1. Out of 806 participants, $59.3 \%$ of the responders were females. Age was subcategorized into four age groups, starting from $<30$ years to $>60$. Of those, $49.4 \%$ were in the age group between 31 to 45 years old. Additionally, $86.1 \%$ of the responses were from the central region in Saudi Arabia, where $60.8 \%$ had a university degree or above, and $61.5 \%$ had a family income between SAR9000 and SAR21000, and 44\% were employed (Table 1).

\subsection{Evaluation of different subscales of the AHRQOL}

Item responses were evaluated and scored based on the five subscales of the questionnaire, including health and activity of daily living, emotion and spiritual domain, work-study domain, social, environmental, 
economic domain, and communication domain to a total score for all domains. The total score was given by adding the item score of AHRQOL and dividing the total by the number of items in the AHRQOL.

Results show that the average total AHRQOL was 285.23 (27.47) out of a maximum score of 350 . The highest average score was achieved in the social, environmental, and economic domains $6.99(0.78)$, while the least average score was achieved in health and activity of daily living domain 5.29 (0.70) (Table 2).

\subsection{Factors predicting the health-related quality of life for adults in Saudi Arabia}

Multivariate linear regression analysis over the five subscales demonstrated that educational level is a significant predictor for all the AHRQOL subscales, while place of residency was a predictor for all the domains except for the health and active daily living. Gender recorded a higher beta value (beta $=-1.90$, $p=0.007$ ) than other predictors for both the Communication domain and Health and Activities of Daily living domain (Table 3).

\section{DISCUSSION}

Health related quality of life has been proposed as the most essential component to measure the overall quality of life of the individual (3). Multiple factors, not only pathological, can influence HRQOL, but social and demographic factors also play a significant role (14). Accordingly, figures of HRQOL for one country cannot be simply applied to another. Although HRQOL has been evaluated in different Western countries, there is a scarcity of data in the medical literature about HRQOL in the Arabic world, particularly Saudi Arabia (15).

Consequently, the present study evaluated the HRQOL among adults living in different regions of Saudi Arabia across ten hospitals. Through a customized questionnaire to suit the Arabic culture and features, it has been revealed that the HRQOL in Saudi Arabia is above average levels. It is important to note that this customized format is expected to provide more accurate information about the Saudi community rather than using standard questionnaires for the evaluation of HRQOL.

HRQOL has been evaluated in different contexts. Al-Aboudi et al. (16) evaluated the HRQOL among diabetic patients in Riyadh, Saudi Arabia. Through a cross-sectional, single-centered study, he demonstrated that patients with type 2 diabetes had a significantly low HRQOL level. He recommended that clinicians consider this low HRQOL when treating this patient population.

On the other hand, the present study did not restrict subjects' inclusion on a specific chronic condition. Any patient who presented for a clinical service for more than three months was eligible for inclusion. The present study was also a multi-center study that recruited almost eight folds the sample size included in Al-Aboudi et al. (16), which suggests higher reliability of the present findings.

Other Saudi studies also evaluated the HRQOL among Saudi population. Al Hayek et al (17) demonstrated that the most significant factors influencing HRQOL in diabetic Saudi patients are economic status, diabetic complications, and gender. Also, Alshehri et al. (18) illustrated that the mode of delivery in Saudi females can significantly affect their HRQoL level. Furthermore, Alshayban et al (19) showed that uncontrolled blood pressure is significantly correlated to reduced quality of life among Saudi hypertensive patients. These findings from Alshayban et al (19) are consistent with Alshayban et al (20) in diabetic patients and support the findings of the present study.

Another systematic review carried out by Wu et al. (21) examined the effect of physical activity on the HRQOL in adolescents. Wu et al. (21) included 31 studies in their review, yet it should be noted that all of them were from western countries. Wu et al. (21) demonstrated an improved HRQOL with increasing physical activity.

The present study demonstrated that the average score for the health and active daily living section was considered the least among all the five included domains (5.29 (0.7)), indicating poor physical activity. Despite this fact, the overall HRQOL in Saudi Arabia adults was generally above average level, with social, environmental, and economic domain showing to be the major contributor for this level. This difference between the present study and Wu et al. (21) confirms HRQOL dependence on different cultural and demographic variables.

A recent study in China by Ping et al. (22) evaluated the HRQOL among the general population during the COVID-19 pandemic. Ping et al. (22) illustrated a reduced HRQOL attributed to an increased prevalence of pain, anxiety, and depression during the pandemic. Ping et al. (22) also showed that other factors contributing to this low HRQOL were aging, lower-income, chronic disease, and worry about getting COVID19. 
Although the present study was performed before the COVID-19 pandemic, HRQOL showed a better level in the Saudi population than the Chinese population. This difference could be attributed to the difference in religious beliefs and attitudes towards life between the two populations.

\section{CONCLUSION}

The health-related quality of life among adults living in Saudi Arabia is above average. Accordingly, these outcomes should be taken into consideration by clinicians treating patients with chronic conditions and public health decision-makers in Saudi Arabia to improve the patients' HRQOL. Future studies should consider a tailored questionnaire to suit the nature of the tested population, which proved to be effective in the present study. This is the first study to evaluate the generic HRQOL among adults with different medical conditions in Saudi Arabia.

\section{Conflict of Interest}

The authors declare no conflict of interest.

\section{REFERENCE LIST}

1.Hajian-Tilaki K, Heidari B, Hajian-Tilaki A. Are Gender Differences in Health-related Quality of Life Attributable to Sociodemographic Characteristics and Chronic Disease Conditions in Elderly People? International journal of preventive medicine. 2017;8:95.

2. Hoehle LP, Phillips KM, Bergmark RW, Caradonna DS, Gray ST, Sedaghat AR. Symptoms of chronic rhinosinusitis differentially impact general health-related quality of life. Rhinology. 2016;54(4):316-22.

3.Vaske I, Kenn K, Keil DC, Rief W, Stenzel NM. Illness perceptions and coping with disease in chronic obstructive pulmonary disease: Effects on health-related quality of life. Journal of health psychology. $2017 ; 22(12): 1570-81$.

4.Obieglo M, Siennicka A, Jankowska EA, Danel DPJJoCN. Direction of the relationship between acceptance of illness and health-related quality of life in chronic heart failure patients. 2017;32(4):34856.

5.Suhaj A, Manu MK, Unnikrishnan MK, Vijayanarayana K, Mallikarjuna Rao C. Effectiveness of clinical pharmacist intervention on health-related quality of life in chronic obstructive pulmonary disorder patients - a randomized controlled study. Journal of clinical pharmacy and therapeutics. 2016;41(1):78-83.

6. Pellisé F, Vila-Casademunt A, Ferrer M, Domingo-Sàbat M, Bagó J, Pérez-Grueso FJ, et al. Impact on health related quality of life of adult spinal deformity (ASD) compared with other chronic conditions. European spine journal : official publication of the European Spine Society, the European Spinal Deformity Society, and the European Section of the Cervical Spine Research Society. 2015;24(1):311.

7. Manavalan M, Majumdar A, Kumar KH, Priyamvada PJljon. Assessment of health-related quality of life and its determinants in patients with chronic kidney disease. 2017;27(1):37.

8. Younossi ZM, Stepanova M, Afdhal N, Kowdley KV, Zeuzem S, Henry L, et al. Improvement of healthrelated quality of life and work productivity in chronic hepatitis $C$ patients with early and advanced fibrosis treated with ledipasvir and sofosbuvir. Journal of hepatology. 2015;63(2):337-45.

9. Schaller A, Dejonghe L, Haastert B, Froboese I. Physical activity and health-related quality of life in chronic low back pain patients: a cross-sectional study. BMC Musculoskelet Disord. 2015;16:62.

10.Varni JW, Bendo CB, Nurko S, Shulman RJ, Self MM, Franciosi JP, et al. Health-related quality of life in pediatric patients with functional and organic gastrointestinal diseases. The Journal of pediatrics. 2015;166(1):85-90.

11.Bagshaw SM, Stelfox HT, Johnson JA, McDermid RC, Rolfson DB, Tsuyuki RT, et al. Long-term association between frailty and health-related quality of life among survivors of critical illness: a prospective multicenter cohort study. Critical care medicine. 2015;43(5):973-82.

12.Ju S, Kim K-SJIJoS, Technology. The relationship among quality of life, depression and subjective health status of the elderly with chronic disease in Korea. 2015;8(16):1-8. 
13.Andrews FM, Withey SB. Social indicators of well-being: Americans' perceptions of life quality: Springer Science \& Business Media; 2012.

14.Karimi M, Brazier J. Health, Health-Related Quality of Life, and Quality of Life: What is the Difference? PharmacoEconomics. 2016;34(7):645-9.

15.Ahmed AE, Alaskar AS, Al-Suliman AM, Jazieh A-R, McClish DK, Al Salamah M, et al. Health-related quality of life in patients with sickle cell disease in Saudi Arabia. Health Qual Life Outcomes [Internet]. 2015 2015/11//; 13:[183 p.]. Available from: http://europepmc.org/abstract/MED/26573908

https://doi.org/10.1186/s12955-015-0380-8

https://europepmc.org/articles/PMC4647668

https://europepmc.org/articles/PMC4647668?pdf=render.

16.Al-Aboudi IS, Hassali MA, Shafie AA, Hassan A, Alrasheedy AA. A cross-sectional assessment of healthrelated quality of life among type 2 diabetes patients in Riyadh, Saudi Arabia. SAGE Open Med. 2015;3:2050312115610129-.

17. Al Hayek AA, Robert AA, AI Saeed A, Alzaid AA, AI Sabaan FS. Factors Associated with Health-Related Quality of Life among Saudi Patients with Type 2 Diabetes Mellitus: A Cross-Sectional Survey. Diabetes \& metabolism journal. 2014;38(3):220-9.

18.Alshehri N, Alanazi A, Alanazi M, Alanazi W, Alanazi J, Alenazi B, et al. Relationship between health related quality of life determinants and type of delivery in Saudi women. 2015;4(1):1-4.

19.Alshayban DM, Joseph R, Alajmi NM, Almarzooq LY, Altamimi WN, Pottoo FH. THE HEATH RELATED QUALITY OF LIFE (HRQOL) FOR HYPERTENSIVE PATIENTS IN EASTERN PROVINCE IN SAUDI ARABIA: CROSS SECTIONAL STUDY.

20. Alshayban $D$, Joseph $R$. Health-related quality of life among patients with type 2 diabetes mellitus in Eastern Province, Saudi Arabia: A cross-sectional study. PloS one. 2020;15(1):e0227573-e.

21. Wu XY, Han LH, Zhang JH, Luo S, Hu JW, Sun K. The influence of physical activity, sedentary behavior on health-related quality of life among the general population of children and adolescents: $\mathrm{A}$ systematic review. PLoS One. 2017;12(11):e0187668.

22.Ping W, Zheng J, Niu X, Guo C, Zhang J, Yang H, et al. Evaluation of health-related quality of life using EQ-5D in China during the COVID-19 pandemic. PLOS ONE. 2020;15(6):e0234850.

Table 1. The socio-demographic data of the responders

\begin{tabular}{|c|c|c|}
\hline Characteristic & N & $\%$ \\
\hline Age & & \\
\hline Less than 30 & 232 & 28.8 \\
\hline $31-45$ & 398 & 49.4 \\
\hline $46-60$ & 107 & 13.3 \\
\hline 60 and above & 69 & 8.5 \\
\hline Gender & & \\
\hline Male & 328 & 40.7 \\
\hline Female & 478 & 59.3 \\
\hline Region & & \\
\hline Central & 694 & 86.1 \\
\hline
\end{tabular}




\begin{tabular}{|c|c|c|}
\hline Western & 11 & 1.4 \\
\hline Southern & 48 & 6.0 \\
\hline Eastern & 31 & 3.8 \\
\hline Northern & 22 & 2.7 \\
\hline \multicolumn{3}{|l|}{ Marital Status } \\
\hline Single & 292 & 36.2 \\
\hline Married & 514 & 63.8 \\
\hline \multicolumn{3}{|l|}{ Education } \\
\hline Non-educated & 11 & 1.3 \\
\hline Primary & 12 & 1.5 \\
\hline Secondary & 89 & 11.0 \\
\hline Tertiary & 205 & 25.4 \\
\hline University and above & 489 & 60.8 \\
\hline \multicolumn{3}{|l|}{ Family income } \\
\hline Less than 9000 & 236 & 29.2 \\
\hline $9000-21000$ & 496 & 61.5 \\
\hline 21000 and above & 74 & 9.3 \\
\hline \multicolumn{3}{|l|}{ Work } \\
\hline Unemployed & 325 & 40.4 \\
\hline Employed & 355 & 44 \\
\hline Student & 126 & 15.6 \\
\hline
\end{tabular}

Table 2. Scores for subscales and total scale of AHRQOL

\begin{tabular}{|c|c|c|c|c|}
\hline Scale & $\begin{array}{c}\text { No. of } \\
\text { items }\end{array}$ & Mean (SD) & Min & Max \\
\hline AHRQoL-G scale & 50 & $285.23(27.47)$ & 118 & 350 \\
\hline $\begin{array}{c}\text { Health and Activity of Daily } \\
\text { Living Domain }\end{array}$ & 12 & $5.29(0.70)$ & 2 & 7 \\
\hline $\begin{array}{c}\text { Emotion and Spiritual } \\
\text { Domain }\end{array}$ & 10 & $6.03(0.67)$ & 2 & 7 \\
\hline
\end{tabular}


Proceedings of INTCESS 2022- 9th International Conference on Education \& Education of Social Sciences 17-18 January 2022- Online Conference

\begin{tabular}{|c|c|c|c|c|}
\hline $\begin{array}{c}\text { Social, environmental, } \\
\text { Economic Domain }\end{array}$ & 10 & $6.99(0.78)$ & 1.8 & 7 \\
\hline Work-Study Domain & 4 & $5.40(1.18)$ & 1 & 7 \\
\hline Communication Domain & 12 & $5.80(0.67)$ & 1.8 & 7 \\
\hline
\end{tabular}

Table 3. Factors predictive of health related quality of life among adult patients in Saudi Arabia using multivariate linear regression analysis

\begin{tabular}{|c|c|c|c|c|c|c|c|c|c|c|}
\hline & \multicolumn{2}{|c|}{$\begin{array}{l}\text { Health and } \\
\text { Activity of } \\
\text { Daily Living } \\
\text { Domain }\end{array}$} & \multicolumn{2}{|c|}{$\begin{array}{l}\text { Emotion and } \\
\text { Spiritual Domain }\end{array}$} & \multicolumn{2}{|c|}{$\begin{array}{c}\text { Social, } \\
\text { environmental, } \\
\text { Economic Domain }\end{array}$} & \multicolumn{2}{|c|}{ Work-Study Domain } & \multicolumn{2}{|c|}{$\begin{array}{c}\text { Communication } \\
\text { Domain }\end{array}$} \\
\hline & $\begin{array}{c}\mathrm{B} \\
(95 \% \mathrm{Cl})\end{array}$ & $\begin{array}{c}\mathrm{p}- \\
\text { value }\end{array}$ & $\begin{array}{c}\mathrm{B} \\
(95 \% \mathrm{Cl})\end{array}$ & $p$-value & $\mathrm{B}(95 \% \mathrm{Cl})$ & $p$-value & $\mathrm{B}(95 \% \mathrm{Cl})$ & $p$-value & $\begin{array}{c}\mathrm{B} \\
(95 \% \mathrm{Cl})\end{array}$ & $\begin{array}{l}\mathrm{p}- \\
\text { value }\end{array}$ \\
\hline Age & $\begin{array}{c}-0.88(- \\
1.68-- \\
0.81)\end{array}$ & 0.031 & $\begin{array}{c}-0.42(- \\
1.07- \\
0.21)\end{array}$ & 0.191 & $\begin{array}{l}-0.19(0.92 \\
-0.52)\end{array}$ & 0.593 & $\begin{array}{l}-0.43(- \\
0.60-- \\
0.26)\end{array}$ & 0.001 & $\begin{array}{l}-0.28(- \\
0.62- \\
0.06)\end{array}$ & 0.116 \\
\hline Gender & $\begin{array}{c}-1.95(- \\
3.24-- \\
0.66)\end{array}$ & 0.003 & $\begin{array}{l}0.02(- \\
1.01- \\
1.05)\end{array}$ & 0.964 & $\begin{array}{c}0.31(-1.47 \\
-0.85)\end{array}$ & 0.598 & $\begin{array}{c}-0.65(- \\
1.28-- \\
0.03)\end{array}$ & 0.040 & $\begin{array}{c}1.54 \\
(0.18- \\
2.80)\end{array}$ & 0.001 \\
\hline Region & $\begin{array}{l}0.46(- \\
0.12- \\
1.05)\end{array}$ & 0.124 & $\begin{array}{l}0.67 \\
(0.20- \\
1.15)\end{array}$ & 0.006 & $\begin{array}{c}1.44(0.85 \\
-1.95)\end{array}$ & 0.001 & $\begin{array}{c}0.38(0.11 \\
--0.65)\end{array}$ & 0.005 & $\begin{array}{c}1.49 \\
(0.98-- \\
2.10)\end{array}$ & 0.026 \\
\hline $\begin{array}{l}\text { Marital } \\
\text { Status }\end{array}$ & $\begin{array}{c}-0.70(- \\
1.66- \\
0.25)\end{array}$ & 0.922 & $\begin{array}{l}0.99(- \\
0.11- \\
2.10)\end{array}$ & 0.079 & $\begin{array}{l}0.21(-1.96 \\
-0.43)\end{array}$ & 0.001 & $\begin{array}{l}0.06(-0.37 \\
-0.49)\end{array}$ & 0.783 & $\begin{array}{l}0.06(- \\
0.83- \\
0.97)\end{array}$ & 0.880 \\
\hline $\begin{array}{l}\text { Educational } \\
\text { attainment }\end{array}$ & $\begin{array}{c}0.70 \\
(0.21- \\
0.78)\end{array}$ & 0.001 & $\begin{array}{l}0.70 \\
(0.33- \\
1.07)\end{array}$ & 0.001 & $\begin{array}{c}0.60(0.14 \\
-1.05)\end{array}$ & 0.009 & $\begin{array}{l}0.67(0.45 \\
-0.89)\end{array}$ & 0.001 & $\begin{array}{c}0.77 \\
(0.31- \\
1.24)\end{array}$ & 0.001 \\
\hline $\begin{array}{l}\text { Family } \\
\text { income }\end{array}$ & $\begin{array}{c}1.33 \\
(0.28- \\
2.38)\end{array}$ & 0.013 & $\begin{array}{l}0.71(- \\
0.12- \\
1.55)\end{array}$ & 0.096 & $\begin{array}{c}0.60(0.23 \\
-0.96)\end{array}$ & 0.001 & $\begin{array}{c}0.15(-0.01 \\
--0.33)\end{array}$ & 0.079 & $\begin{array}{l}0.27(- \\
0.09- \\
0.64)\end{array}$ & 0.148 \\
\hline $\begin{array}{l}\text { Employment } \\
\text { status }\end{array}$ & $\begin{array}{l}0.11(- \\
0.83- \\
1.06)\end{array}$ & 0.816 & $\begin{array}{c}-0.30(- \\
1.06- \\
0.46)\end{array}$ & 0.441 & $\begin{array}{c}-0.40(- \\
0.73-- \\
0.07)\end{array}$ & 0.018 & $\begin{array}{c}-0.91(- \\
1.07-- \\
0.75)\end{array}$ & 0.001 & $\begin{array}{l}-0.52(- \\
0.86- \\
0.18)\end{array}$ & 0.002 \\
\hline
\end{tabular}

